\title{
Perhitungan Analisis Sistem Nodal Untuk Menentukan Laju Alir Minyak Dengan Meningkatkan Range Efesiensi Electric Submercible Pump Pada Sumur di Lapangan Minyak PT. BOB. BSP - Pertamina Hulu
}

\author{
Ali Musnal ${ }^{1}$, Richa Melisa ${ }^{1}$ \\ ${ }^{1}$ Program Studi Teknik Perminyakan Universitas Islam Riau
}

\begin{abstract}
Abstrak
Dengan berjalannya waktu produksi, tekanan reservoir akan mengalami penurunan. Untuk mengatasi hal tersebut diatas dipergunakan pengangkatan buatan yang dikenal dengan "Artificial Lift". Pada sumur di BOB PT.BSP- Pertamina Hulu Zamrud pada umumnya mempergunakan pompa electric submercible pump (ESP) sebagai pengangkatan buatan. Pompa ESP ini pada periode tertentu juga mengalami penurunan kemampuan untuk mengangkat fluida. Hal ini disebabkan karena berkurangnya kemampuan dari tekanan reservoir, terjadinya over load atau under load pada pompa, karena jumlah stages yang dipasang tidak tepat, dan disamping itu terjadinya kerusakan pada peralatan produksi itu sendiri.

Penelitian ini menghitung Range efesiensi pompa terpasang, mengevaluasi kemampuan pompa ditandai besarnya laju produksi, menghitung jumlah stages dan Horse power pompa yang terpasang. Perhitungan mempergunakan metoda Analisa System Nodal, dimana titik nodalnya terletak didasar sumur. Berdasarkan hasil perhitungan range efesiensi pompa dari 4 sumur kajian, terdapat 2 pompa yang bekerja sesuai range efesiensinya dan pompa pada 2 sumur lainnya yaitu sumur F-02 dan F-04 mempunyai laju produksi $2500 \mathrm{stb} / \mathrm{d}$ dan $1450 \mathrm{stb} / \mathrm{d}$. Pompa ini bekerja di bawah range efisiensi kalau kondisi ini diabaikan terus akan terjadi kerusakan pada pompa karena "downthrust" pada sumur F-02 dan F-04 agar meningkatkan laju produksi dan menghindari pompa bekerja pada kondisi downtrush maka dari hasil analisa sebaiknya ditambahkan panjang stage dari 44 stage menjadi 75 stage pada sumur F-02 dan 120 stage menjadi 150 stage pada sumur F-04.
\end{abstract}

Kata Kunci: Range Efesiensi, Laju Produksi, PI, Stage dan Horse Power.

Corresponding author e-mail: alimusnal@eng.uir.ac.id

\section{PENDAHULUAN}

Untuk memenuhi Kebutuhan bahan bakar minyak (BBM) di Indonesia, upaya yang dilakukan mencari sumur baru. Mengoptimasikan ladang sumur minyak yang ada dan dapat juga dilakukan menggunakan energi terbarukan seperti biofuel, matahari, angin, dan lain sebagainya. Laju produksi minyak di setiap sumur lapangan Minyak dengan berjalannya waktu produksi akan menurun. Hal ini disebabkan karena turunnya tekanan reservoir seperti yang dikemukakan sebelumnya dan beberapa sumur sudah mempunyai water cut yang tinggi, sehingga gradien di dalam tubing menjadi lebih besar/berat. Pengangkatan buatan (artificial lift) dilakukan untuk membantu memproduksikan minyak di lapangan. Pemilihan metode artificial lift yang tepat sangat diperlukan untuk memperoleh produksi minyak yang optimum. Pada lapangan minyak BOB PT. BSP - Pertamina Hulu sudah memakai pompa Electric Submercible Pump (ESP) untuk pengangkatan buatan.

Untuk pengoperasiannya, pompa ESP di lapangan minyak, seringkali ditemukan permasalahan ketidaksesuaian laju produksi yang diinginkan (secara teoritis) dengan laju produksi yang sebenarnya (efisiensi pompa rendah), sehingga diperlukan suatu evaluasi terhadap kinerja pompa tersebut untuk mendapatkan kinerja pompa yang maksimal efisiensinya. Dari sekian banyak areal lapangan minyak BOB PT. BSP - Pertamina Hulu, peneliti hanya mengambil data dari areal Beruk North yang mempunyai 10 sumur dan keseluruhan sumur mempergunakan pompa ESP sebagai pengangkatan buatan. Peneliti melakukan 4 sumur kajian, karena dari 4 sumur ini mempunyai data yang cukup sebagai bahan penelitian. 


\section{TUJUAN PENELITIAN}

Tujuan dari penelitian ini, yaitu :

1. Menghitung produktivitas indeks (PI) setiap sumur kajian.

2. Menghitung besarnya range efisiensi pompa terpasang

3. Menghitung besarnya laju produksi untuk setiap sumur kajian.

4. Menghitung jumlah stages pompa dan Horse Power yang dibutuhkan pompa.

\section{METODE PENELITIAN}

Metode dalam penelitian ini dilakukan dengan merujuk ke referensi yang berhubungan dengan permasalahan. Kemudian diaplikasikan pada lapangan sumur minyak dengan melakukan terjun lansung ke lapangan untuk mengumpulkan data-data lapangan, setelah itu memproses data dan mengevaluasi untuk mendapatkan gambaran efisiensi pompa terpasang. Sudah banyak dilakukan penelitian mengenai pompa ESP seperti mengevaluasi ESP, optimasi laju produksi dengan pompa ESP, perencanaan ulang pompa terpasang dan lain sebagainya. Pada penelitian ini difokuskan menekan range efisiensi pompa ESP, di samping melihat kemampuan sumur untuk berproduksi.

\section{TEORI DASAR}

Nodal adalah suatu titik pertemuan antara dua performance aliran yang berbeda pada sumur produksi. Digambarkan dalam bentuk grafik tekanan dan laju alir produksi minyak.

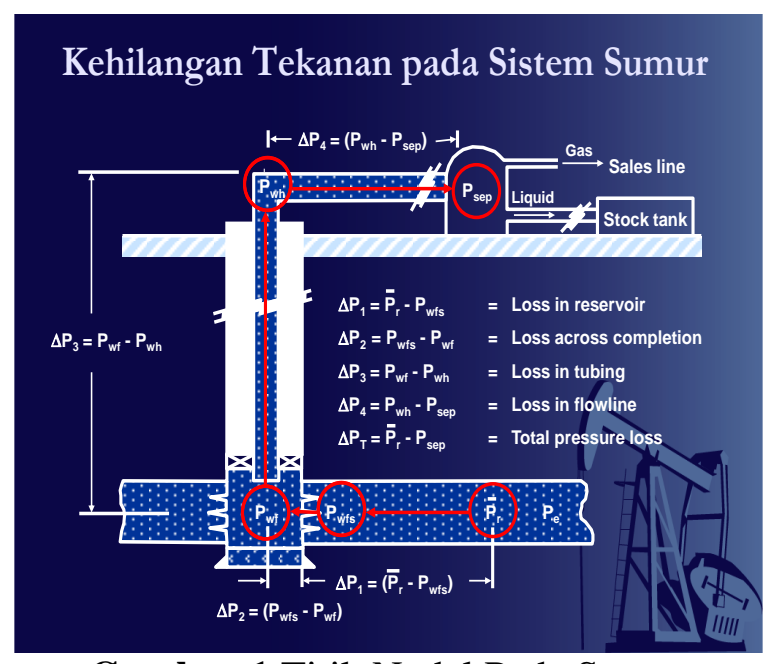

Gambar 1 Titik Nodal Pada Sumur

\section{Sistem Nodal Pada Elecric Submercible Pump}

Perhitungan analisa nodal untuk pompa electric submercible pump ini, titik nodalnya terletak di dasar sumur yaitu menghubungkan tekanan tubing intake stages pompa dengan kurva inflow performance relationship, seperti contoh gambar di bawah ini 


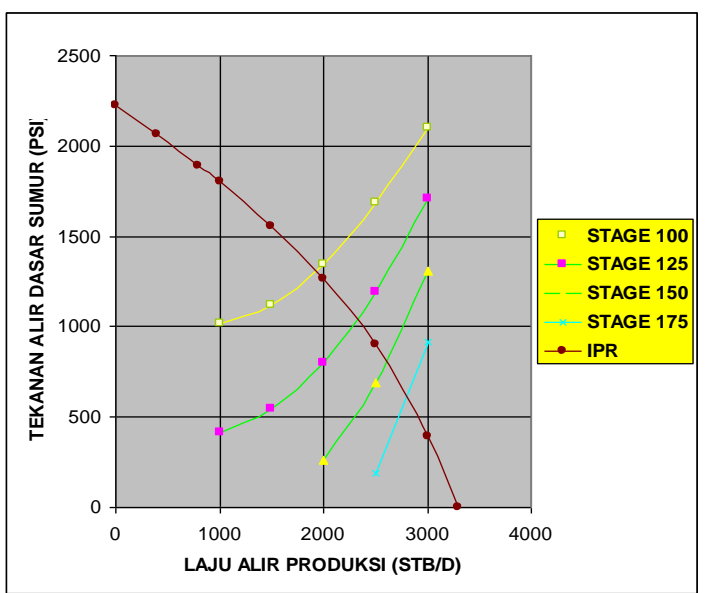

Gambar 2 Kurva Tubing Intake Untuk ESP

\section{Prinsip Kerja Pompa ESP}

Prinsip dasar dari Electrical Submersible Pump adalah dengan mengalirkan fluida dari satu tingkat ke tingkat selanjutnya, dimana pompa ini terdiri dari bagian yang berputar (impeller) dan tempat fluidanya (diffuser). Impeller melakukan pengisapan fluida dari bawah untuk diteruskan ke diffuser dan fluida yang ada di diffuser kemudian akan dialirkan lagi ke bagian atas (impeller). Apabila tingkat (stage) digunakan lebih banyak, maka kepala motor/rumah stage akan lebih tinggi. Proses ini berulang beberapa kali dan tergantung pada jumlah tingkatnya. Tiap tingkat yang digunakan menentukan volume fluida yang akan dipindahkan.

\section{Productivity Index (PI)}

Productivity Index (PI) adalah suatu indeks yang menyatakan kemampuan sumur untuk mengangkat fluida ke permukaan pada kondisi tekanan tertentu. Dapat juga dikatakan sebagai perbandingan laju produksi yang dihasilkan oleh suatu sumur dengan perbedaan tekanan Draw down Pressure secara matematis dapat dituliskan sebagai berikut:

dimana:

$$
\mathrm{PI}=\mathrm{J}=\frac{\mathrm{q}}{(\mathrm{Ps}-\mathrm{Pwf})}
$$

PI $\quad=\mathrm{J}=$ Productivity Index, $\mathrm{bbl} / \mathrm{day} / \mathrm{psi}$

$\mathrm{Q} \quad=$ Laju Produksi Aliran Total, bbl/day

Ps $\quad=$ Tekanan Statis Reservoir, Psi

Pwf $=$ Tekanan Dasar Sumur saat terdapat Aliran, Psi

\section{Inflow Performance Relationship (IPR) Curve}

Inflow Performace Relationship (IPR) Curve yaitu suatu kurva yang mengambarkan prilaku aliran fluida dari reservoir ke dasar sumur.Kurva tersebut dibuat harga tekanan alir dasar sumur (Pwf) versus laju alir $(\mathrm{Q})$ yang dihasilkan.

Persamaan metode Vogel adalah sebagai berikut:

atau

$$
\frac{\mathrm{q}}{\mathrm{q}_{\max }}=1-0,2\left(\frac{\mathrm{P}_{\mathrm{wf}}}{\mathrm{P}_{\mathrm{s}}}\right)-0,8\left(\frac{\mathrm{P}_{\mathrm{wf}}}{\mathrm{P}_{\mathrm{s}}}\right)^{2}
$$




$$
\mathrm{P}_{\mathrm{wf}}=0,125 \mathrm{Ps}\left[\sqrt{81-80\left(\frac{\mathrm{q}}{\mathrm{q}_{\max }}\right)-1}\right]
$$

Harga $\rho_{\text {fsc }}$ dihitung dengan persamaan sebagai berikut :

$\rho_{f s c}=350 W C \gamma_{w}+350(1-W C) \gamma_{o}+G I P(G L R) \rho_{g s c}$

dimana $\rho_{\mathrm{gsc}}$ adalah densitas gas pada kondisi standar.

\section{Perhitungan Jumlah Tingkat Pompa Elektrik}

Jumlah Stage (St) dapat dihitung dengan persamaan berikut ini.

$$
S t=\left[\frac{808,3141}{\rho_{f s c} h}\right]\left(P_{2}-P_{3}\right)
$$

atau

$$
P_{3}=P_{2}-\left[\frac{\rho_{f s c} h}{808,3141}\right] S t
$$

Sedangkan Horse Powernya dapat dihitung dengan persamaan

$$
H P=\left[\frac{1}{0,433}\right] \frac{h P}{h}\left(P_{2}-P_{3}\right)
$$

Jika persamaan diatas disubtitusikan akan menghasilkan persamaan berikut

$$
\mathrm{HP}=h p \cdot \gamma f s c . \mathrm{St}
$$

\begin{tabular}{|c|c|c|c|}
\hline Pr, Psi & 1800 & Dalam sumur, $\mathrm{ft}$ & 3510 \\
\hline Laju Produksi , Bfpd & 4580 & Casing size, in & $9-5 / 8$ \\
\hline Q Maks , Stbl/d & 5.708 & Tubing size, in & $3-1 / 2$ \\
\hline Flowing temp, $\mathrm{F}$ & 300 & PWH, Psi & 1000 \\
\hline$\Gamma g$ & 0,65 & $\begin{array}{l}\text { Wellhead Temp } \\
\text { F }\end{array}$ & 268 \\
\hline$\Gamma \mathrm{w}$ & 1,065 & API & 35 \\
\hline Water Cut & $92.0 \%$ & $\Gamma \mathrm{o}$ & 0,812 \\
\hline $\mathrm{Pb}, \mathrm{Psi}$ & 1700 & GOR , Scf / Stbo & 600 \\
\hline H P Pompa & $160 \mathrm{HP}$ & Stage & $\begin{array}{l}68 \\
\text { Stg }\end{array}$ \\
\hline Type Pompa & GN-5600 & Amp & $8.5 \mathrm{~A}$ \\
\hline
\end{tabular}

\section{DATA SUMUR DAN ANALISA PERHITUNGAN}

Tabel 1 Data Sumur F-01 Dan Data Pompa

\section{Perhitungan Produktifitas Indeks dan Kurva IPR}

Perhitungan Produktifitas Index :

$$
\begin{aligned}
& P_{w f}=0,125 \cdot \operatorname{Pr} \cdot[-1+\sqrt{81-80 \cdot(\text { Qac } / Q M a k s)}\rfloor \\
& P_{w f}=0,125 x 1800 \cdot[-1+\sqrt{81-80 \cdot(4580 / 5708)}]
\end{aligned}
$$




$$
\begin{aligned}
\mathrm{P}_{\mathrm{wf}} & =697,48 \mathrm{Psi} \\
\mathrm{Pi} & =\mathrm{Q} /\left(\mathrm{Pr}-\mathrm{P}_{\mathrm{wf}}\right) \\
& =4580 /(1800-697,48) \\
& =4.15 \mathrm{stb} / \mathrm{d} / \mathrm{psi}
\end{aligned}
$$

Perhitungan kurva IPR:

$$
P_{w f}=0,125 . P r \cdot[-1+\sqrt{81-80 \cdot(\text { Qass } / \text { QMaks })}]
$$

Untuk Laju Alir $(\mathrm{Q})=800 \mathrm{stb} / \mathrm{d}$;

$P_{w f}=0,125 . \operatorname{Pr} .[-1+\sqrt{81-80 .(800 / 5708)}]=1655$ Psi

Tabel 2 Hasil Perhitungan Pwf

\begin{tabular}{|c|c|c|c|}
\hline $\begin{array}{c}\text { Q (Stb/d) } \\
\text { Asumsi }\end{array}$ & PWF(Psi) & $\begin{array}{c}\text { Q (Stb/d) } \\
\text { Asumsi }\end{array}$ & PWF(Psi) \\
\hline 0 & 1800 & 3500 & 1047 \\
\hline 800 & 1655 & 4000 & 899 \\
\hline 1500 & 1517 & 4500 & 727 \\
\hline 2000 & 1412 & 5000 & 520 \\
\hline 2500 & 1300 & 5500 & 220 \\
\hline
\end{tabular}

Tabel di atas di plot Q versus Pwf, hasilnya grafik di bawah ini.

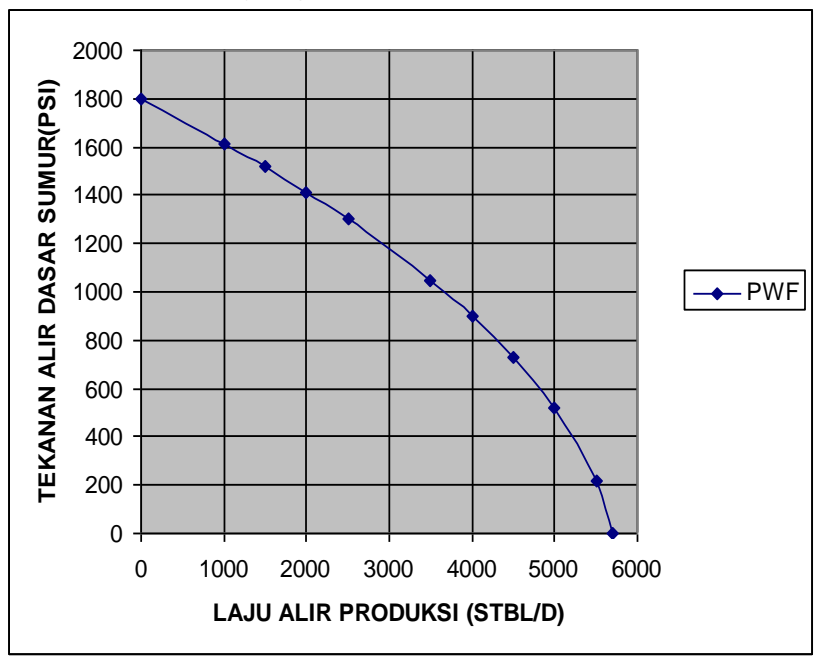

Gambar 3 Kurva Inflow Performance Relationship

\section{Perhitungan Tekanan Intake Pompa}

$$
\begin{aligned}
\rho f s c & =350 . \text { WC. } \gamma \mathrm{wsc}+350 .(1-\mathrm{WC}) \cdot \gamma \text { osc } \\
& =350 .(0,92) \cdot(1,065)+350 .(1-0,92) .(0,812) \\
& =365.6 \mathrm{lb} / \mathrm{stb} \\
P_{3}=P_{2} & -\left[\frac{\rho_{f s c} h}{808,314}\right] \text { St }
\end{aligned}
$$


$P_{3}=2410-\left[\frac{365.6 \times 39}{808.314}\right] 100$

$P_{3}=646 P s i$

Tabel 3 Hasil Perhitungan Untuk Q dan P3 Berbagai Stage

\begin{tabular}{|c|c|c|c|c|c|c|}
\hline \multirow{2}{*}{ Q } & \multirow{2}{*}{ P2 } & \multirow{2}{*}{ h } & \multicolumn{5}{|c|}{ P3 @ } \\
\cline { 4 - 7 } & & & St =100 & St =125 & St=150 & St=175 \\
\hline 1500 & 2390 & 43 & 445 & -40 & -527 & -1013 \\
\hline 2000 & 2400 & 41 & 546 & 82 & -381 & -844 \\
\hline 2500 & 2410 & 39 & 646 & 205 & -235 & -676 \\
\hline 3500 & 2577 & 38 & 859 & 429 & 0,54 & -430 \\
\hline 4000 & 2669 & 37 & 996 & 577 & 159 & -259 \\
\hline 4500 & 2760 & 35 & 1177 & 782 & 386 & -10 \\
\hline 5000 & 2853 & 32 & 1406 & 1044 & 682 & 321 \\
\hline 5500 & 3027 & 31,5 & 1602 & 1246 & 890 & 534 \\
\hline
\end{tabular}

Setelah diplot antara Q dan P3 untuk berbagai Stage, maka didapat Gambar 4

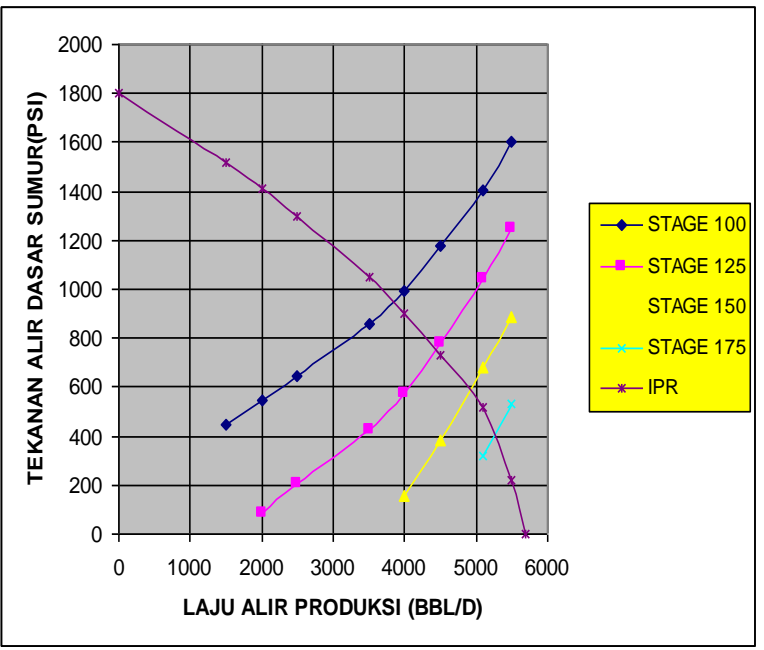

Gambar 4 Kurva Tubing Intake Untuk ESP

\section{Perhitungan Range Efesiensi}

Menentukan HP :

$(\not f s c) V=\frac{Q_{S C} \cdot \rho f s c}{350 . V}$

$\mathrm{V}=\mathrm{Qsc}$ 


$$
\begin{aligned}
& (\not f s c)=\frac{\rho f s c}{350} \\
& (\not f s c)=\frac{365.6}{350} \\
& (\not f s c)=1.044 \\
& H P=(\not f s c) x(h p) x(s t) \\
& H P=1.044 x(h p) x(s t)
\end{aligned}
$$

Tabel 4 Perhitungan Horse Power dengan Berbagai Jumlah Stage

\begin{tabular}{|c|c|c|c|}
\hline $\mathbf{S t}$ & $\mathbf{Q p}$ & $\mathbf{H P}$ & HP Total \\
\hline 100 & 3,975 & 1.59 & 166 \\
\hline 125 & 4,500 & 1.61 & 210 \\
\hline 150 & 4,975 & 1.69 & 265 \\
\hline
\end{tabular}

Berdasarkan performance pompa type Gn 5,600 mempunyai kapasitas Range efesiensi 4,000 sampai dengan 7,250 stb/d, maka pilihan terbaik kapasitas untuk pompa ini sebesar 5,000 stb/d.

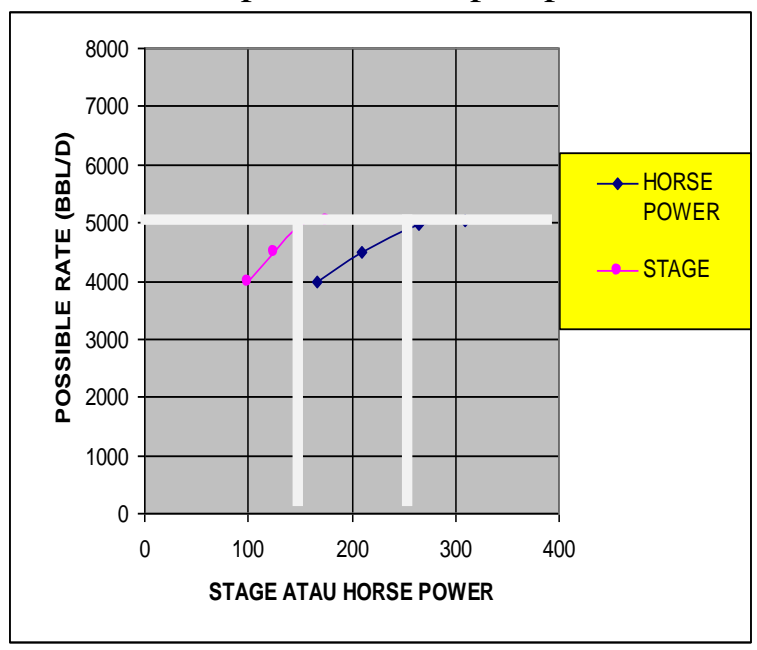

Gambar 5 Laju Alir Yang Mungkin Terhadap Stage dan Horse Power

Jadi dari pembacaan gambar 5 untuk QP = 5,000 STBL/D, maka didapat :

$$
\begin{array}{ll}
\text { JUMLAH STAGE } & =160 \text { Stage } \\
\text { TOTAL HP } & =280 \text { Horse Power }
\end{array}
$$

Berdasarkan performance pompa type SN 2,600 mempunyai kapasitas range efisiensi 1,750 sampai dengan 3,250 stb/d, maka pilihan terbaik kapasitas untuk pompa ini sebesar 2,500 stb/d.

Untuk QP = 2,500 STBL/D dengan Tekanan Discharge = 3,688 psi, maka didapat :

\section{JUMLAH STAGE $=150$ Stage}




\section{PEMBAHASAN}

Berdasarkan hasil perhitungan yang telah dilakukan pada 4 sumur kajian, maka pada tabel dibawah ini pada masing masing sumur kajian terlihat kondisi sumur real dilapangan dan hasil perhitungan dengan mempergunakan analisa sistim nodal, berikut ini akan dibahas untuk masing masing sumur:

Tabel 5 Kondisi Real dan Hasil Perhitungan

\begin{tabular}{|c|c|c|c|c|c|c|c|c|c|}
\hline \multirow{2}{*}{ Sumur } & \multirow{2}{*}{$\begin{array}{c}\text { Type } \\
\text { Pompa }\end{array}$} & \multicolumn{2}{|c|}{ Kondisi Lapangan } & \multicolumn{4}{c|}{ Hasil Analisa Perhitungan } & \multirow{2}{*}{ PI } \\
\cline { 4 - 9 } & Stage & HP & $\begin{array}{c}\text { Laju } \\
\text { Alir } \\
\text { Q(stb/d) }\end{array}$ & Stage & HP & $\begin{array}{c}\text { Laju } \\
\text { Alir } \\
\text { Q(stb/d) }\end{array}$ & $\begin{array}{c}\text { Range } \\
\text { Efisiensi }\end{array}$ & (stb/d/psi) \\
\hline f1 & gn-5600 & 68 & 160 & 4580 & 160 & 280 & 5000 & $4000-7250$ & 4,15 \\
\hline f2 & sn-3600 & 44 & 120 & 2500 & 75 & 135 & 3250 & $3200-4500$ & 5,7 \\
\hline f3 & sn-8500 & 86 & 280 & 6283 & 175 & 450 & 6000 & $6000-$ & 3,8 \\
\hline f4 & sn-2600 & 75 & 120 & 1450 & 150 & 185 & 2600 & $1750-3250$ & 20,8 \\
\hline
\end{tabular}

Untuk sumur F1 berdasarkan performance pompa type Gn 5600 mempunyai kapasitas Range efesiensi 4000 sampai dengan $7250 \mathrm{stb} / \mathrm{d}$, maka pilihan terbaik kapasitas untuk pompa ini sebesar $5000 \mathrm{stb} / \mathrm{d}$, karena selain menghasilkan tekanan drawdown yang reasonable juga pompa beropersasi disekitar puncak efesiensi.Berdasarkan data lapangan pompa ini bekerja berada pada range efisiensi yang baik.

Sumur F2 menggunakan tipe pompa SN 3600, Berdasarkan performance pompa type SN 3600 ini mempunyai kapasitas Range efesiensi 3200 sampai dengan 4500 stb/d, maka pilihan terbaik kapasitas untuk pompa ini sebesar $3250 \mathrm{stb} / \mathrm{d}$, pompa ini bekerja dibawah range efisiensi. Laju Produksi di lapangan sebesar $2500 \mathrm{stb} / \mathrm{d}$, hal ini kalau dibiarkan berjalan terus akan mengakibatkan pompa akan rusak, karena pompa bekerja pada kondisi Downtrush.

Sumur F3 mempergunakan pompa ESP type SN 8500, Berdasarkan performance pompa type SN 8500 mempunyai kapasitas Range efisiensi $6000 \mathrm{stb} / \mathrm{d}$ sampai dengan $11000 \mathrm{stb} / \mathrm{d}$, maka pilihan terbaik kapasitas untuk pompa ini sebesar 6000 stb/d.sedangkan dilapangan besarnya laju produksi sebesar $6283 \mathrm{stb} / \mathrm{d}$, jadi pompa ini bekerja pada kondsi range efisiensi.

Sumur F4 mempergunakan type pompa SN 2600, berdasarkan performance pompa type ini mempunyai kapasitas Range efisiensi 1750 sampai dengan $3250 \mathrm{stb} / \mathrm{d}$, maka pilihan terbaik kapasitas untuk pompa ini sebesar $2500 \mathrm{stb} / \mathrm{d}$, karena harga ini mendekati puncak range efisiensi. Data kondisi dilapangan menunjukkan besarnya laju produksi $1450 \mathrm{stb} / \mathrm{d}$, berarti pompa bekerja dibawah range efisiensi, kalau kondisi ini dibiarkan terus menerus pompa akan cepat rusak karena downtrush. Bila dilihat kemampuan sumur masih memungkin untuk dilakukan peningkatan produksi.

Kondisi real dengan hasil perhitungan terdapat perbedaan stage, horse power pompa dan laju produksi. Pompa dalam kondisi baik untuk semua sumur kajian, pada sumur F-02 dan F-04 agar meningkatkan 
laju produksi dan menghindari pompa bekerja pada kondisi downthrust maka dari hasil analisa sebaiknya ditambahkan panjang stage dari 44 stage menjadi 75 stage pada sumur F-02 dan 120 stage menjadi 150 stage pada sumur F-04.

\section{KESIMPULAN DAN SARAN}

Berdasarkan hasil perhitungan yang telah dilakukan dengan menggunakan analisa sistem nodal di dasar sumur dan pembahasan, maka dapat disimpulkan sebagai berikut :

1. Untuk sumur F1 menggunakan pompa type Gn 5600, kapasitas range efisiensi 4000 sampai dengan $7250 \mathrm{stb} / \mathrm{d}$, laju produksi $4580 \mathrm{stb} / \mathrm{d}$, pompa ini bekerja pada range efisiensi yang baik beropersasi disekitar puncak efisiensi.

2. Sumur F2 menggunakan tipe pompa SN 3600 mempunyai kapasitas range efisiensi 3200 sampai dengan 4500 stb/d, Laju Produksi dilapangan sebesar 2500 stb/d, pompa ini bekerja dibawah range efisiensi, jika dibiarkan berjalan terus akan mengakibatkan pompa akan rusak, karena pompa bekerja pada kondisi " Downtrush ".

3. Sumur F3 mempergunakan pompa ESP type SN 8500, mempunyai kapasitas range efisiensi 6000 stb/d sampai dengan $11000 \mathrm{stb} / \mathrm{d}$, sedangkan dilapangan besarnya laju produksi sebesar $6283 \mathrm{stb} / \mathrm{d}$, jadi pompa ini bekerja pada kondsi range efisiensi.

4. Sumur F4 mempergunakan type pompa SN 2600, mempunyai kapasitas range efisiensi 1750 sampai dengan $3250 \mathrm{stb} / \mathrm{d}$, data kondisi di lapangan menunjukkan besarnya laju produksi $1450 \mathrm{stb} / \mathrm{d}$, berarti pompa bekerja di bawah range efisiensi, jika kondisi ini dibiarkan terus menerus pompa akan cepat rusak karena downthrust.

5. Kondisi real dengan hasil perhitungan terdapat perbedaan stage, horse power pompa dan laju produksi. pompa dalam kondisi baik untuk semua sumur kajian, pada sumur F-02 dan F-04 agar meningkatkan laju produksi dan menghindari pompa bekerja pada kondisi downtrush maka dari hasil analisa sebaiknya ditambahkan panjang stage dari 44 stage menjadi 75 stage pada sumur F-02 dan 120 stage menjadi 150 stage pada sumur F-04.

\section{SARAN}

- Berdasarkan hasil penelitian ini dapat disaran kepada perusahaan tempat penelitian dilakukan bahwa ; sumur F2 dan F4 produksinya harus dinaikan didalam efisiensi range yang direkomandasikan pompa, untuk menghindari pompa tidak cepat rusak.

- Untuk Peneliti selanjutnya disarankan melakukan kajian analisa keekonomiannya, karena pada penelitiannya ini ada perubahan terahadap laju produksi, jumlah stages dan horse power pompa.

\section{DAFTAR PUSTAKA}

Brown, K.E. (1977). The Technology of Artificial Lift Methods", volume 1. Tulsa: PennWell Publishing Co.

Brown, K.E. (1980). The Technology of Artificial Lift Methods, volume 2B. Tulsa: PennWell Publishing Co.

Brown, K.E. (1984). The Technology of Artificial Lift Methods, volume 4. Tulsa: PennWell Publishing Co.

Suwardi, F. (2015). Evaluasi Pompa ESP Terpasang Untuk Optimasi Besarnya Laju Produksi Minyak Universitas Sriwijaya.

Putra,Andri. Evaluasi Dan Optimasi Pompa Electric Submercible Pump. Tri Jurnal Lemlit Trisakti.

Widiyanto, G. 2010. Optimasi Pompa Pada Dewatering Sumur CMB.

Daniel Hill. Petroleum Production Systems. 
Pirson. (1992). Oil Reservoir Engineering.

Sukarno, Pudjo. (1990). Production Optimalization with Nodal System Analysis. Jakarta: PT. Indrilco Sakti.

Nind, T.E.W. (1959). Principle of Oil Well Production (2nd ed). New York: Mc-Graw Hill. 